\title{
GLAD!
}

Revue sur le langage, le genre, les sexualités

05 | 2018

Raconter les sexualités depuis la marge

\section{Myriam Joël. 2017. La sexualité en prison de femmes}

\section{Laélia Véron}

\section{(2) OpenEdition}

Journals

Édition électronique

URL : http://journals.openedition.org/glad/1201

ISSN : 2551-0819

Éditeur

Association GSL

Référence électronique

Laélia Véron, « Myriam Joël. 2017. La sexualité en prison de femmes », GLAD! [En ligne], 05 | 2018, mis en ligne le 15 décembre 2018, consulté le 17 décembre 2020. URL : http://journals.openedition.org/ glad/1201

Ce document a été généré automatiquement le 17 décembre 2020.

\section{(c) $(1) \Theta$}

La revue GLAD! est mise à disposition selon les termes de la Licence Creative Commons Attribution Pas d'Utilisation Commerciale - Pas de Modification 4.0 International. 


\title{
Myriam Joël. 2017. La sexualité en prison de femmes
}

\author{
Laélia Véron
}

\section{RÉFÉRENCE}

Myriam Joël. 2017. La sexualité en prison de femmes. Paris : Sciences Po Presses. 286 pages.

1 L'ouvrage de Myriam Joël, La sexualité en prison de femmes, est tiré de sa thèse de sociologie, menée sous la direction de Philippe Combessie. Ce travail s'appuie sur une étude qualitative menée pendant deux ans, dans divers établissements carcéraux. M. Joël s'est entretenue avec 250 personnes évoluant dans le monde carcéral : des femmes détenues bien entendu, mais aussi des surveillantes et des surveillants et des intervenant·es extérieure's. En effet, cet ouvrage n'étudie pas uniquement «la sexualité des femmes détenues » mais bien «la sexualité en prison de femmes » (p. 23) et s'intéresse ainsi aux "constellations très diverses de pratiques, d'interactions, d'émotions et de représentations » (Bozon, 2001, p. 15) touchant à la sexualité, telles qu'elles apparaissent dans les relations entre les différents acteurs et actrices du monde carcéral féminin.

2 Étudier la sexualité en prison de femmes implique de prendre en compte une multitude de spécificités institutionnelles que souligne M. Joël : alors que la prison est un lieu «façonné par la logique du masculin» (Malochet, 2005, p. 217) la prison de femmes est un lieu quasiment non mixte, le QF (Quartier Femmes) étant d'ailleurs très souvent spatialement excentré. La sexualité en détention est encadrée par une loi particulièrement ambiguë, l'article R 57-7-2 du CPP (Code de Procédure Pénale): «Constitue une faute disciplinaire (...) le fait, pour une personne détenue (...) d'imposer à la vue d'autrui des actes obscènes ou susceptibles d'offenser la pudeur ». La sexualité n'est donc pas interdite : c'est la visibilité de la sexualité qui l'est (ce qui se manifeste par la censure, qu'il s'agisse de la censure du courrier ou des actes jugés démonstratifs). Mais cette visibilité est définie subjectivement par des termes négatifs, qui relèvent de 
la libre appréciation de certains acteurs et actrices (notamment les personnes chargées de la surveillance). C'est autour de cette tension entre ce qui est montrable et non montrable, dicible et non dicible, que M. Joël organise les trois parties de son ouvrage («Une sexualité clandestine », p. 27-83 ; «Une sexualité invisible», p. 85-146; «Une sexualité ostentatoire ", p. 147-270).

3 L'ouvrage de M. Joël a l'intérêt de détailler non seulement les résultats de son enquête, mais aussi les difficultés qu'elle a pu rencontrer : comment échanger sur un sujet tabou (la sexualité, qui plus est la sexualité féminine) dans un lieu où l'expression de la sexualité peut être rapidement jugée illégale ? La sociologue s'est ainsi confrontée à la gêne des surveillantes et des surveillants, notamment des hommes âgés, à la résistance marquée du personnel soignant (pour lequel il pouvait s'agir de sujets touchant au secret professionnel) et à toutes sortes d'obstacles avec les personnes détenues. Après avoir essuyé un semi-échec en proposant un questionnaire qui représentait un outil visiblement inadapté à un tel objet de recherche (plusieurs questions étant laissées sans réponses, les cases libres étant au contraire abondamment remplies), M. Joël a choisi de mener des entretiens semi-directifs. Trouver des participantes s'est également avéré difficile, que ce soit à cause de l'objet de recherche lui-même, de l'administration qui tendait à écarter les détenues analphabètes ou handicapées, ou encore du stigmate attaché aux détenues ayant commis des crimes sur mineurs et à toute personne impliquée dans un échange familier avec elles. Interroger les détenues sur leurs pratiques et leurs conceptions de la sexualité pose ainsi des problèmes récurrents de choix de langage. L'enquêteuse et l'enquêtée ne partagent pas forcément le même jugement d'une part sur les pratiques jugées ou non taboues (M. Joël montre ainsi que l'homosexualité est bien stigmatisée en prison de femmes, contrairement à ce que certaines représentations clichées laissent supposer p. 163-165) et d'autre part sur le caractère problématique des questions posées durant l'entretien: M. Joël explique comment les détenues se sont montrées plus choquées par des questions sur la pratique de la masturbation et de la sodomie que sur les abus sexuels (p. 118 et 154-157). Le choix des termes pour désigner ces pratiques s'est montré sans cesse un «exercice périlleux " (p.156), le recours à des termes techniques ou argotiques présentant diverses difficultés. Le vocabulaire sociologique, par exemple la distinction entre turnouts et true homosexuals introduite par certaines études américaines (p.138-139), présente lui aussi des insuffisances pour décrire les expériences vécues par les détenues.

4 Cet ouvrage, à la fois riche et réflexif, peut présenter le défaut d'éparpiller quelque peu principes méthodologiques et définitions (ainsi la définition des types d'incarcération et des stratégies auxquels ils correspondent n'apparaît qu'à la page 40, la nuance du terme générique "prison » à la page 168). Mais la démarche inductive adoptée par M. Joël, doublée d'une permanente remise en question, permet de remettre en cause bon nombre de clichés, aussi bien sur la sexualité féminine, sur la prison, que sur les personnes détenues. Cet ouvrage, passionnant, permet d'approcher le poids normatif d'une prison qui devient un "puissant relais du modèle légitime de sexualité féminine » (p. 259). 


\section{BIBLIOGRAPHIE}

MALOCHET, Guillaume. 2005. «Dans l'ombre des hommes. La féminisation du personnel de surveillance des prisons pour hommes » Sociétés contemporaines 59-60 : 199-200.

BOZON, Michel. 2001. «Orientations intimes et constructions de soi. Pluralité et conflits dans les expressions de la sexualité » Sociétés contemporaines 41-42:11-40.

INDEX

Thèmes : Actualités

Mots-clés : sexualité, détention, prison, enquête sociologique, tabou, légitimation

Keywords : sexuality, detention, sociological investigation, taboo, legitimation

\section{AUTEURS}

\section{LAÉLIA VÉRON}

Laélia Véron est agrégée de Lettres Modernes, docteure en langue et littérature françaises et maîtresse de conférences en stylistique à l'Université d'Orléans. Elle est également enseignante en milieu carcéral. 